
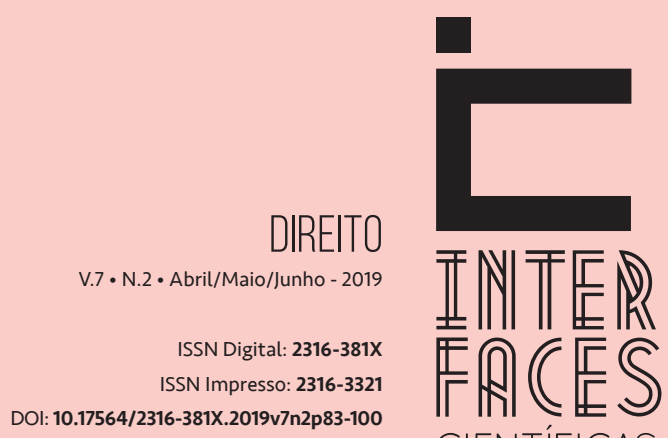

CIENTÍFICAS

\section{MAIS DIREITOS HUMANOS E MENOS MISANTROPIA: POR UM DIREITO MENOS EGOÍSTA}

MORE HUMAN RIGHTS AND LESS MISANTROPY: FOR A LEAST SELFISHRIGHT

MÁS DERECHOS HUMANOS Y MENOS MISANTROPIA: POR UN DERECHO MENOS EGOÍSTA

\section{RESUMO}

Por revisão bibliográfica qualitativa descritiva, perlustra-se neste artigo, em certo caráter filosófico-ensaístico, teorias que possam dizer, em tom crítico, qual o atual modelo de Direito, precipuamente de Direitos Humanos, e quais os possíveis caminhos rumo a um futuro com mais Justiça Social, sustentabilidade, responsabilidade social, cidadania, democracia e liberdade. Defende-se ser preciso que o homem seja menos egoísta, seja solidário, respeite seu Outro e que elimine sua atual misantropia, a fim de viva em paz com seu congênere e, juntos, busquem todos um mundo melhor.

\section{PALAVRAS-CHAVE}

Mais Direitos Humanos. Menos misantropia. Direito. Egoísmo. Análise. 


\section{ABSTRACT}

For a descriptive qualitative bibliographical review, we explore in this article, in a certain philosophical-essayistic character, theories that can tell us, in a critical tone, what our current model of Law is, fundamentally Human Rights, and what are the possible paths towards a future with more Social Justice, sustainability, social responsibility, citizenship, democracy and freedom. We defend that it is necessary for man to be less selfish, to be solidary, to respect his Other and to eliminate his present misanthropy, in order to live in peace with his counterpart and together, let us all seek a better world.

\section{KEYWORDS}

More Human Rights. Less misanthropy. Selfishness. Law. Analysis.

\section{RESUMEN}

Por revisión bibliográfica cualitativa descriptiva, se recorre en este artículo, en cierto carácter filosófico-ensayístico, teorías que puedan decir, en tono crítico, cuál es el actual modelo de Derecho, precipuamente de Derechos Humanos, y cuáles son los posibles caminos hacia un futuro con más Justicia Social, sostenibilidad, responsabilidad social, ciudadanía, democracia y libertad. Se defiende que es preciso que el hombre sea menos egoísta, sea solidario, respete a su Otro y que elimine su actual misantropía, a fin de vivir en paz con su congénere y, juntos, busquen a todos un mundo mejor.

\section{PALABRAS CLAVE}

Más derechos humanos. Menos misantropía. La ley. El egoísmo. Análisis. 


\section{INTRODUÇ̧̃̃o}

Está estampado no dicionário eletrônico Houaiss (2009) que misantropia é um "ódio pela humanidade", uma "falta de sociabilidade", ou seja, um comportamento mesquinho, hipócrita e ardil que possui o ser humano que não ama seu próximo, não deseja o bem de seu congênere, não quer que ele seja feliz, tenha saúde, educação, alimentação, um trabalho digno, enfim Direitos Humanos básicos. Nessa perspectiva, crê-se que, atualmente, o Direito ocidental, a dita "Ciência" Jurídica, subsiste sobre uma base social egoística e misantrópica. Excetuando-se as pouquíssimas circunstâncias em que o Direito é bom, na maioria das vezes a "Ciência" juris serve para elevar dentro do homem seu egoísmo e seu egocentrismo.

Vive-se sob a égide de um Direito que é egoísta, que prega o individualismo exacerbado, que enaltece a ridícula meritocracia, que transforma pessoas em "partes" de uma engrenagem (o Poder Judiciário), que convola seres humanos em objetos do "grande” capital, precificando a vida, a honra, o meio ambiente, com multas, fianças e outras perversidades. Que se utiliza de ideologias para mascarar as coisas/verdades e sancionar, perseguir, humilhar e explorar principalmente negros, indígenas, homossexuais, brancos pobres, mulheres entre outros.

Está-se sobre espaço e tempo ocidentais mais democráticos do que nunca, mas, de revés, também mais autocráticos do que em qualquer outro momento. Somos todos ditadores de nós mesmos a nos isolarmos em caixinhas sociais, em grupos, em ideologias. Essa carga individualista da democracia

[...] tem vindo a ser [...] revalorizada dentro de uma concepção de Estado que parece reforçar a substância ideológica do individualismo ao mesmo tempo que apoia a visão 'libertária' [...] dos direitos integrados num contexto de liberdade de mercado. (ESTEVÃO, 2006, p. 87-88).

Pensar sobre tais questões, por revisão bibliográfica qualitativa, é o objetivo deste singelo artigo

\section{QUE SÃO DIREITOS HUMANOS?}

Ao leitor leigo, que não teve a experiência inefável de sentar as nádegas nos bancos de uma graduação em Direito, apreendendo narrativas e ideologias nefastas várias, Direitos Humanos são, à evidência, Direitos do Homem, do Ser Humano. Esta inferência está correta! Bastando, para complementar a ideia, lembrar-se que

A discussão internacional sobre direitos humanos se iniciou logo após o genocídio imposto pelo nazismo na Segunda Guerra, culminando com a Declaração Universal dos Direitos Humanos de 1948 e ratificada na Declaração Universal de Direitos Humanos de Viena, em 1993. (FERNANDES; PALUDETO, 2010, p. 234). 
Estas declarações trazem ao mundo uma percepção de Direitos Humanos universais e indivisíveis e foram criadas com o (suposto) fito de conscientizar o mundo de que as pessoas, apenas por serem humanas (não animais irracionais), merecem tratamento digno, "humano". Fernandes e Paludeto (2010), relendo Marshall (1967), lembram que para este teórico britânico os Direitos Humanos são, basicamente, os direitos civis, políticos e sociais.

Dizem as pesquisadoras:

Os direitos civis referem-se às liberdades individuais, liberdade de ir e vir, liberdade de imprensa, pensamento e fé, o direito à propriedade e à conclusão de contratos válidos e o direito à justiça. São os tribunais de justiça que garantirão os direitos civis, através da igualdade perante a lei. Os direitos políticos garantem a participação dos indivíduos no exercício do poder político, ora como membros de um organismo investido de autoridade política (partidos, sindicatos, associações), ora como eleitores dos membros de tal organismo. As instituições encarregadas de garantir estes direitos são o Parlamento e as câmaras representativas locais. Finalmente, os direitos sociais referem-se ao bem-estar econômico e segurança ao direito de participar, por completo, na herança social, levando uma vida de ser civilizado de acordo com os padrões que prevalecem na sociedade (consumo, lazer, segurança). 0 sistema educacional e os serviços sociais deverão garantir estes direitos. A educação é um pré-requisito necessário à liberdade civil, pois os direitos civis se destinam a ser utilizados por pessoas inteligentes e de bom senso, que aprenderam a ler e escrever (FERNANDES; PALUDETO, 2010, p. 234).

Vê-se que, então, os Direitos Humanos são os direitos básicos/basilares de que dispõem as pessoas.

São direitos fundamentais do homem, caracterizando-se como verdadeiras liberdades positivas, de observância obrigatória em um Estado Social de Direito, tendo por finalidade a melhoria das condições de vida aos hipossuficientes, visando à concretização da igualdade social. (MORAES, 2002, p. 202).

"São os direitos que, consagrados na Constituição, representam as bases éticas do sistema jurídico nacional” (COMPARATO, 2003, p. 176). Tais direitos são belos, contudo, hoje em dia pouco implemento e vigor possuem. No mundo inteiro há milhares de pessoas com fome, presas em inocência delitual, privadas de condições mínimas de vida, em escravidão laboral. Como lembrou Lyra (2015, p. 15),

A justiça, em regra, castiga pobres e miseráveis, [...] desgraçados pelos exemplos ricos [...] e pelas pressões da necessidade e do abandono. Diante de um crime 'bárbaro', as autoridades dirigem-se aos lugares em que vegetam os humildes. São eles os suspeitos.

Infelizmente, assim se comporta o Direito (neo)liberal burguês do século XXI. 


\section{UMA ESPERANÇA PARA A HODIERNA SOCIEDADE MISANTRÓPICA: A EDUCAÇÃO JURÍDICA}

Crê-se ser necessário, atualmente e para o futuro, que o ser humano esteja mais disposto a conviver com o Outro, com seu semelhante. A permitir-se ser alterado por ele (alteridade). A estar mais aberto ao mundo, às opiniões e "verdades" dos outros, como propôs Heidegger em sua fenomenologia, ao dizer que "a abertura se constitui de disposição, de compreender e de falar [...] por isso, somente com a abertura da presença é que se alcança o fenômeno mais originário da verdade" (HEIDEGGER, 2006, p. 291).

É necessário que o homem, notadamente o povo (os pobres), se diferencie da burguesia que traiu os mais fracos. Esta burguesia hipócrita, egoísta em inefável medida, como cantou Cazuza, e que, como disse Lafargue (2000) - ao analisar que tal classe quando lutava contra a nobreza, apoiada pelo clero, ia de encontro ao Cristianismo, pregava o ateísmo, glorificava a carnalidade da vida e suas paixões, mas mudou de ideia e, hoje, cumulada de riquezas e bens, se apoia na religião para legitimar seus prazeres.

Essa burguesia que vai às igrejas pedir carro, casa com piscina, viagens etc., e que quando aufere tais coisas, pela exploração de terceiros, diz que foi “Deus quem deu”, chegando a alocar adesivos nas traseiras de veículos com tal ideia/frase. 0 povo precisa ser diferente dessa burguesia egoísta. Pensa-se que no caminho do extermínio (ou por ora atenuação) do egoísmo que tem impedido o homem de prover direitos básicos ao seu semelhante, portanto Direitos Humanos, uma boa ideia é que os cidadãos busquem se qualificar no processo de busca por seus direitos.

Os que têm condições devem estudar. Estudar, entre muitas coisas, o Direito. Devem ser, entre várias profissões, advogados. Advogar em causa própria, advogar para os parentes, para pessoas pobres, para os vizinhos, para os moradores de rua, para os negros e brancos desempregados, para os indígenas aviltados em direitos, para mulheres em violência. Mas, como assim, sem ganhar nada? Bem, cada um conhece seu coração².

É Fato que, por exemplo, no Brasil, as elites que comandam o Estado e, por conseguinte, o Ministério da Educação, estão cada vez mais relutantes em permitir a abertura de mais cursos jurídicos no país. Alegam ser necessário que as faculdades e universidades se enquadrem em vários requisitos, criam uma burocracia negativa. Ao lado disso, a OAB, querendo o monopólio da profissão advocatícia e a manutenção da percepção de milhões de reais com anuidades, também se queda contrária ao fim do Exame de Ordem, o qual integra, ainda, verdadeiro comércio de cursinhos preparatórios, manuais, livros etc.

Porém, malgrado tudo isso, sim, é interessante que as pessoas estudem Direito, porquanto decerto:

[...] havendo mais advogados, estes terão de vender seus serviços por preços menores, de forma a poderem ser contratados pela população mais pobre (cujas demandas nunca serão atendidas de forma completa pela Defensoria Pública, principalmente se pensarmos que a tendência, pelo menos para os próximos anos, é no sentido da redução da intervenção do Estado). Havendo mais advogados, haverá também um maior conhecimento de Direito circulando na sociedade. (JUNQUEIRA, 1999, p. 99-100).

20 novo Código de Ética da OAB, válido a partir de 2016, inovou ao permitir, no seu Art. 30, a advocacia pro bono (defesa gratuita de pobres), antes rechaçada pela elitista $O A B$. 
Devemos estudar, pois “[...] se não soubermos como funciona o poder e quem o detém, dificilmente conseguiremos propor mudanças e atuarmos na construção de uma sociedade mais justa [...]. Só podemos ser livres se desatarmos as amarras do poder hegemônico que negamos" (SILVA, 2012, p. 22). Temos de estudar, mas devemos, também, lembrar que toda educação sempre será uma educação para o trabalho, afinal a educação visa, em si mesma, à reprodução das diversas mãos de obra. Necessitamos, portanto, estudar, todavia, saindo pela tangente, usar a educação para buscar artimanhas dentro do próprio sistema que nos encobre desproporcionalmente. Nessa via de direção, no caso do Direito:

Eis o momento de se propor um saber inserido na historicidade, resultado de uma relação de conhecimento do jurista com o mundo e, voltando-se para o futuro, apto a formular conceitos teórico-práticos para mudá-lo [o mundo]. Um saber que, conhecendo o direito positivo, explique-o teoricamente, a sua lógica e o seu funcionamento, ao mesmo tempo em que, captando-o como resultante de relações de poder, promova e reclame a afirmação dos direitos necessários à defesa e à promoção da dignidade humana [...]. (ALVES NETO, 2012, p. 71).

\section{A SOLIDARIEDADE COMO ALAVANCA DA PROMOÇÃO DOS DIREITOS HUMANOS}

É necessário que o homem seja (mais) solidário para com seu próximo. Solidariedade remete a sólido. Dizem vários autores que a solidariedade é tudo aquilo que objetiva tornar a sociedade sólida, bem, estável. Portanto, dar comida ao faminto, por exemplo, é uma boa forma de tornar seu viver sólido, estável, harmônico, posto que as pessoas necessitam de comida, de energia, de força. Devemos, então, usar do que Schopenhauer (2001) chamou de "egoísmo esclarecido". Para o filósofo, o egoísmo moderado é aceitável, pois até o corpo humano internamente é egoísta - quando uma parte está ferida todos os esforços se concentram nela. Assim, para que o ser humano viva bem e feliz é preciso mesclar cuidar de si com cuidar do Outro.

Isso é a mesma coisa que Skinner (1971), relido por Abib (2001), chama de "pacifismo". Para o pacifismo é "necessário descobrir, inventar e fortalecer práticas que promovam a sobrevivência dos indivíduos e das culturas [...] [pois] defender o pacifismo é engajar-se em práticas que promovem [...] cooperação, apoio, solidariedade, tolerância, compaixão" (ABIB, 2001, p. 110-111).

Nesse caminho, devemos sim respeitar as leis - algumas delas são relevantíssimas. Se não houvesse coação estatal, certamente, ficaríamos deitados o tempo inteiro - o que não seria ruim. Porém, devemos lutar por nossos direitos, contra normas que exacerbadamente tentem nos limitar no acesso a recursos de que necessitamos - a usufruirmos de nossos Direitos Humanos. Não podemos atribuir tudo a Deus ou dele cobrar providências. Agindo assim, estaremos negando a história. É na sociedade e suas lutas onde (o)corre a vida.

Devemos ter consciência dos discursos que nos rodeiam, das artimanhas e ideologias dos poderosos. Devemos problematizar nossas realidades. Pensar como seria se as coisas fossem diferentes, 
bem como estudar como as coisas foram no pretérito, o que nos trouxe até aqui (?). No quesito "Estado jurídico", uma boa inspiração são os indígenas. 0 Cacique, o líder político das tribos, não ganha nada para chefiar a vivência coletiva, bem como, malgrado seja o líder, geralmente não tem soberania, posto que tudo é decidido coletivamente. Encontrar um limiar tênue entre a existência do Estado, das leis e da verdadeira liberdade do povo é missão para os próximos séculos.

Para galgarmos mais solidariedade humana, não falamos em destruir o capitalismo ou as instituições do Estado liberal, nem tampouco em buscar um mundo socialista, comunista ou anarquista. Esse monte de coisas já se tentou em várias partes do mundo e foi um fracasso - por causa do egoísmo dos líderes revolucionários e suas ideias totalitárias. Afinal,

[...] construir o socialismo não é o mesmo que substituir o Estado comandado pelos monopólios privados por um sistema capitalista estatal [...], [sendo preciso, na verdade,] criar condições em terra para que todas as nossas evidentes diferenças individuais se desenvolvam fraternalmente. (SIQUEIRA, 2009, p. 14).

Como aduz o professor Fábio Konder Comparato, o ideal é a criação de um novo modelo de vida, totalmente diferente do atual, o que ele chama de "pós-capitalismo", sobre o que assevera:

[...] [é preciso] suscitar [...] no meio acadêmico e fora dele, o trabalho coletivo de construção de um modelo de civilização pós-capitalista. Para tanto, é preciso suscitar uma nova mentalidade coletiva e criar novas instituições sociais [...]; advertindo-se que, enquanto a mudança de mentalidade é, sobretudo, um trabalho de educação coletiva, a mudança de instituições sociais pressupõe a montagem de uma nova estrutura de poderes. Ora, como o capitalismo é a primeira civilização mundial surgida na história, o pós-capitalismo aponta, necessariamente, para a construção de uma sociedade política do gênero humano, com base em três princípios fundamentais: 1) o princípio republicano, com predominância absoluta do bem comum sobre os interesses particulares; 2) o princípio democrático, assegurando-se ao conjunto dos povos a titularidade do poder soberano; e 3) o princípio do Estado de Direito, por força do qual todos os poderes, incluindo o soberano, são necessariamente limitados, submetendo-se o seu exercício aos ditames do sistema universal de direitos humanos. (COMPARATO, 2011, p. 274).

Nesse contexto, temos de nos desprender do atual sistema que nos oprime e sermos mais livres. A fim de sermos mais livres, é preciso uma "[...] visão integrada dos conceitos oriundos da Filosofia, da Antropologia, da Psicologia e da Sociologia para ampliação do conceito usual de liberdade” (ABREU, 2012, p. 137) que temos.

Isso, porquanto:

A ampliação da liberdade figura entre os maiores anseios do ser humano, e a liberdade já obtida um dos mais valiosos, inferior apenas à manutenção da vida. As pessoas que alcançaram 
maio nível de liberdade são vistas com misto de admiração e desconfiança ${ }^{3}$. [...]. Contudo, o tratamento da liberdade como fenômeno genérico não passa de abstracionismo: o que há são liberdades. Uma mulher pode ser alta executiva, cujas decisões afetam a existência de milhares de funcionários, e ocupar uma posição subalterna no espaço doméstico, em decorrências da cultura patriarcal; ou o "chefe de família" comporta-se como tiranete em casa, enquanto no espaço produtivo submete-se de maneira servil aos ditames patronais. (ABREU, 2012, p. 141).

Temos realmente que buscar sermos mais livres. Devemos fixar em nossas mentes que "a liberdade diz respeito à escolha entre diferentes possibilidades, cujas chances de concretização são diretamente proporcionais ao poder do agente [...]" (ABREU, 2012, p. 142). Pensando assim, logo concluiremos que um ponto fulcral de nossas sociedades é a forma de distribuição de poder. É o poder quem liberta e, portanto, precisamos dividir (mais) o poder entre todos.

Devemos, atenuando nosso egoísmo, efetivamente ajudar, dentro de nossas limitações, as pessoas que sofrem, que não têm o que comer, um meio de transporte, saúde, chance de ir à escola, de tomar banho diariamente. Estas pessoas que têm o choro como rotina. Aqueles sobre quem Walter Benjamim, rememorado por Siqueira (2009, p. 45), disse: "para os de baixo a catástrofe não é algo por ocorrer, mas elemento da vida corrente".

Precisamos voltar aos valores bons - apenas os bons - que exsurgiram com o iluminismo. Valores tais que "a burguesia tende a abandonar sempre que entram em conflito com o dinheiro" (SIQUEIRA, 2009, p. 49). Devemos ter em mente que, por nossa atual configuração de Estado e de Direito, problemas graves virão num futuro próximo. Existem gargalos em quase todas as áreas humanas relacionadas ao Direito. A saúde, o meio ambiente, a segurança pública; praticamente há um colapso em tudo.

Devemos buscar, da forma como pudermos colaborar, “uma democracia substantiva, ou seja, que extrapole os estreitos limites da igualdade formal” (SIQUEIRA, 2009, p. 100), bem como devemos vencer a hipocrisia e cretinice dos que tentam "convencer-nos de que a desigualdade é o preço a pagar pela liberdade política [se é que temos isso], não havendo nada que se possa fazer para alterar este estado de coisas" (SIQUEIRA, 2009, p. 101).

\section{A NECESSÁRIA ASSUNÇÃO DAS CRISES HUMANAS}

Temos de assumir o plexo de crises em que estão nossas sociedades, notadamente a crise econômica/política-jurídica, e buscar alternativas humanas para solucioná-las. Como bem expõe Comparato (2011, p. 273):

A grande crise financeira mundial que eclodiu em 2008 veio demonstrar que a civilização capitalista apresenta claros sintomas de esgotamento. Desde 1980, a parte corresponden-

3 Os artistas famosos, por exemplo, ou mesmo pessoas não famosas, que se vestem de forma excêntrica, sem se enquadrarem nas normas sociais (padrões) são visto com desconfiança. Perguntamos sempre: será que são “loucos”? 
te aos rendimentos de capital na formação do produto mundial não cessa de aumentar, enquanto a dos rendimentos do trabalho, assalariado ou autônomo, continua a decrescer. 0 aumento do desemprego em âmbito mundial, provocado pela mencionada crise, ainda não manifestou sinais de reabsorção. Quase que instantaneamente vimos reproduzida, no interior de cada país, a fratura aberta no plano internacional entre países desenvolvidos e subdesenvolvidos. 0 novo sistema de transnacionalidade empresarial, aliás, muito tem contribuído para tanto, ao promover grandes deslocamentos de empresas, dos antigos países desenvolvidos para os novos países ditos "emergentes". Além disso, ele faz que uma empresa dominante, com sede em determinado país, estabeleça relações de senhorio e servidão com outras em várias partes do mundo, obrigando as empresas servas a operar em sistema de dumping social e negação dos mais elementares direitos trabalhistas. Ao mesmo tempo, nessa fase de hegemonia incontrolada do capitalismo financeiro, verifica-se, no mundo todo, uma inquietante redução dos investimentos produtivos, em relação ao total das riquezas produzidas. Todos esses fatos compõem o quadro típico de uma verdadeira crise, no original sentido hipocrático do termo: o momento exato em que o olhar experiente do médico observa uma mudança súbita no estado do paciente, para o bem ou para o mal; o instante em que se declaram, nitidamente, os sintomas da moléstia, permitindo o diagnóstico e o prognóstico.

Não temos aqui, nem seria jamais esta a nossa volição, uma receita de comportamento ou moral padrão a serem postos em prática, a fim de alçarmos melhores condições de vida neste planeta para todos. Não sabemos qual queria uma solução final pronta e acabada, porque ela não existe, mas sabemos o que é necessário fazer no aqui e agora, no presente e isso tem a ver com educar nossas crianças, com ser correto, respeitar a todos, a todas as religiões, orientações sexuais, condições de gênero, ligações político-partidárias etc. Tem a ver com sermos menos egoístas, individualistas. É um esforço complexo, sabemos, mas é a nossa alternativa mais reluzente no prisma de um futuro mais justo.

Apraz que enxerguemos o fato de que hoje vivemos um tempo em que o conjunto das decisões políticas, que devem ser tomadas diariamente para nosso bem:

[...] na prática passa por uma minoria da elite que manipula a consciência da maioria, porque detém o poder político e econômico e todo o aparato instrumental à sua disposição, como os meios de comunicação de massa, a tecnologia e o próprio sistema educacional estabelecido. A esperança é a de que, apesar do poder manipulador das elites, a sociedade brasileira - representada por alguns políticos decentes e compromissados com o bem-estar social de todos - consiga vencer o preconceito, o racismo, a intolerância e a prepotência de poucos. (LUCIANO, 2006, p. 164).

Sabemos que "viver junto necessariamente produz problemas, oportunidades, direitos e obrigações econômicas compartilhadas por todos os envolvidos" (ZELIZER, 2009, p. 150) e, nesse sentido, devemos buscar ser mais afetuosos e compreensíveis com o Outro. Parar e ponderar se atitudes egoísticas, acumuladoras, menosprezadoras do meio ambiente, entre outras, são de fato, verdadeiramente, 
interessantes quando olhamos ao redor e vemos tanta gente sem ter comida, saúde, enfim conditios mínimas de vida, de respiração, de fôlego, de dignidade; Direitos Humanos!

Precisamos mudar. Como assevera Bakhtin (2014, p. 340), falando sobre o "mundo moderno" e seus defeitos:

A esse pequeno mundo condenado a perecer, onde as pessoas estão separadas, são egoisticamente fechadas e gananciosamente práticas, onde o trabalho é diversificado e mecanizado, onde objetos não dependem do trabalho pessoal, se opõe um mundo vasto, mas abstrato. É preciso construir esse mundo vasto sobre uma base nova, torná-lo familiar, humanizá-lo. É preciso encontrar uma nova relação com a natureza, não com a pequena natureza do recanto familiar, mas com a vasta natureza do mundo imenso, com todos os fenômenos do sistema solar, com as riquezas retiradas das entranhas da terra, com a diversidade geográfica dos países e dos continentes. (Grifos nossos)

Devemos nos desacompanhar dos velhos ideais "modernos”. Jogar fora as maléficas ideias “[...] que acompanham até hoje o discurso comum da filosofia do direito: individualismo, [...] universalidade dos direitos ${ }^{4}[. .$.$] " (MASCARO, 2008, p. 21). Precisamos entender que em nossas vidas, além de nos$ importarmos conosco mesmos, devemos, também, caminhar ao lado de ideias coletivistas. Precisamos pensar mais no Outro.

Temos de ter cautela como nossos próprios pensamentos, com nossa filosofia, problematizá-la. Perceber e lembrar que "a quebra das razões feudais fez da filosofia do direito moderna uma filosofia progressista em face do passado [...] [mas] [...] seu individualismo universalista e seu caráter burguês dela fizeram uma filosofia conservadora em face do futuro" (MASCARO, 2008, p. 48).

Devemos viver mais a vida na sua prática, nas ruas, respirar o ar das comunidades, ir aos lugares improváveis, aonde jamais iríamos; visitar os lugares mais pobres, ver filas nos hospitais. Como disse Marx, rememorado por Mascaro (2008), quem não se incursiona sobre a práxis (a vida prática) vive totalmente desperspectivizado. Assim, precisamos ter e buscar perspectivas. Cremos que somente a bruteza das injustiças da vida tem a capacidade de clarear as retinas de quem ainda não parou e pensou em seu egoísmo mórbido.

Precisamos fugir do Estado mínimo adorado pelas elites, elites tais integradas por indivíduos que “[...] exigem que o Estado seja o simples braço armado das camadas privilegiadas" (LOSURDO, 1998, p. 118 apud MASCARO, 2008, p. 130). Temos de compreender que não é a filosofia que faz o mundo, mas o contrário, assim acordaremos para a realidade de ser preciso viver a vida prática, a vida das ruas, lutar por nossos direitos. Digerir nossas leis no asfalto, nos ramais, nas periferias.

Nessa perspectiva, devemos correr de vãs filosofias e superficiais amores e relações humanos. A superficialidade, universalização e generalização de qualquer coisa precisam ser combatidas. Devemos levantar a bandeira do viver do homem concreto, "real". Como ensina o professor Mascaro: "A defesa da justiça como defesa da humanidade genérica, do homem genérico e não do homem concreto (desprovido do acesso efetivo à distribuição das necessidades), é a defesa filosófica bem

4 No sentido de "leis universais". 
acabada que os tempos reacionários e neoliberais conseguem empreender" (MASCARO, 2008, p. 133) e precisamos ir além disso.

Devemos acreditar em um mundo melhor. Isso não pode ser um defeito. Cremos que um dos passos iniciais de tal conduta é respeitar o Outro. Viver ao lado do outro e não atrás dele, o perseguindo, ou à frente dele, correndo. Viver lastreado no que Habermas (2003) chama de "agir comunicativo". "Para Habermas a validade de todo o Direito e o próprio conceito de Justiça devem derivar de uma discussão plural, onde todas as ideias, ainda que antagônicas, possam ser livremente expostas dentro das regras de um jogo democrático" (CABETTE, 2014, p. 49).

No Brasil existe uma elite descendente dos europeus hipócritas que aqui chegaram para matar indígenas e extrair todas as riquezas que existiam - acabaram com o Pau-Brasil, plantaram cana para fazer açúcar, extraíram ouro aos montes, aqueles que hoje revestem as enormes igrejas e templos do velho continente. Tal elite acha-se dona do país. Crê veementemente ser o grupo mais capaz de governar a nação. Precisamos mostrar a ela que temos voz, reivindicar nossos direitos, nossos Direitos Humanos.

\section{POR UM NOVO OLHAR SOBRE A VIDA E O DIREITO}

Cremos, mediante todo o exposto, para fugir de sermos enganados e controlados pelos poderosos, como agora estamos sendo em meio a tanta corrupção política, ser preciso agir na vida, usando o que Beatriz Sarlo, inspirada em vários autores, chama de olhar político. Para ela "o olhar político segue a moral de não passar ao largo de si mesmo; aponta e recorda a história de sua composição, das desigualdades e das clivagens sociais que figuram entre suas condições de possibilidade” (SARLO, 1997, p. 59).

Tal olhar político, diz a autora argentina, é um modo de enxergar a vida não apenas como nos é dada, pronta e acabada, mas de um modo inabitual. É um olhar que traça oposição aos discursos, ideologias, morais e estéticas estabelecidos. “Um olhar político aguça a percepção das diferenças como qualidades alternativas frente às linhas respaldadas pela tradição estética ou pela inércia do mercado" (SARLO, 1997, p. 60). Enfim, olhar para as coisas politicamente, diz a autora, é desvelar as fissuras do que é consolidado, rupturas estas que nos mostram o caminho das mudanças.

A pesquisadora deixa claro que:

Um olhar político trabalharia com o aparentemente descabido, na medida em que o descabido não responde às indagações consideradas legítimas. Sensível às diferenças e ao novo, um olhar político não se dedica a organizar um cânone, mas se mantém suspenso na trama das exceções, das propostas apenas escoçadas, das iniciativas que recusam a carga do hábito. [...] o olhar político atenta na alternativa e esboça percursos entre as formas dispersas e, às vezes, inaudíveis do novo. Descobre e relaciona [...] nas vozes dispersas da alternativa e da dissidência. [...] Um olhar político tem várias possibilidades de foco, que, por sua vez, desencadeiam diversos tipos de preocupações e de discurso. [...]. (SARLO, 1997, p. 61-62). 
Precisamos usar esse tipo de olhar na procura de novas posturas e novas atitudes frente ao necrófilo egoísmo que nos envolve. Posturas, pois pensamentos, mudanças paradigmáticas. Atitudes, pois ações efetivas, viradas da realidade. Cremos tudo começar mesmo com a educação e o respeito pelo próximo. Respeitando-o não queremos o que é dele, bem como com tal respeito, também, estaremos pensando nele, posto que para respeitá-lo precisamos nele pensar, pensar sobre ele, avaliá-lo positivamente, permitirmo-nos ser alterados por ele.

"É preciso um novo olhar sobre aqueles que são diferentes de nós por partilhar de outras crenças, pertencer a outras classes sociais, ter raízes históricas distintas, enfim, por se guiar por suas lógicas e seus valores próprios" (GRUPIONI, 2001, p. 23). Isso, pois, somente, reconhecendo a diferença do Outro podemos atribuir a ele a condição de cidadão, o que remete à compulsoriedade maior da cidadania: a pluralidade.

Precisamos buscar "[...] uma nova ética, a ser construída de forma conjunta, na qual seja possível afirmar a verdadeira convivência com a diferença” (GRUPIONI, 2001, p. 24). Nessa direção, devemos forjar o mais breve possível análises e debates direcionados a responder à seguinte questão central: quais as condições necessárias para garantir ao mesmo tempo a igualdade e o respeito às diferenças?

Nesse caminho:

O desafio que se nos coloca, então, é o de como pensar a diferença. Diferença entre povos, culturas, tipos físicos, classes sociais: estará fadada a ser eternamente compreendida e vivida como desigualdade [a diferença]? Como relações entre superiores e inferiores, evoluídos e primitivos, cultos e ignorantes, ricos e pobres, maiores e menores, corretos e incorretos, com direitos e sem direitos? [...] Respeito à diferença, saber conviver com os que não são exatamente como eu sou ou como eu gostaria que eles fossem e fazer das diferenças um triunfo, explorá-las em sua riqueza, possibilitar a troca, o aprendizado recíproco, proceder, como grupo, à construção [...]. Tudo isto descreve desafios. (LOPES SILVA; GRUPIONI, 1995, p. 17-18 apud GRUPIONI, 2001, p. 24).

Devemos todos, absolutamente todos, não sermos tão egoístas. Não pensarmos tanto em dinheiro, em bens, em valores, em quantidades. Nem tudo é quantidade. Roma certa vez perdeu mais de 40 mil soldados para 300 homens de Cartago. Precisamos pensar mais na qualidade. Não devemos ter preço e sim valor, posto que somos únicos. Irrepetíveis. Tudo o que tem preço é substituível.

Acreditamos ficar a mensagem final de que é necessário cada vez mais tecer novas narrativas sobre a humanidade, sobre o Direito, sobre a história e sobre a vida. Nesse rumo, reputamos por bem que estas narrativas, quando escritas, constituam-se como:

Uma escrita que incomode a quem lê e também a quem produz. Um texto que nos retire de nosso conforto, uma história que não seja escrita em redes de dormir, em poltronas e cadeiras de balanço, nas varandas ou debaixo das árvores no quintal. Um texto que seja agudo, penetrante, que não deseje amaciar, acarinhar ou envolver sem sobressaltos ao leitor. É preciso escrever um texto [...] que fira, que provoque dor ao trazer para a cena 
os eventos e personagens que foram feridos, magoados, que doloridos viveram vidas de resto e de rastro. Uma história que trate dos homens e mulheres que viveram vidas ásperas e rústicas. Uma narrativa [...] que dilacere os objetos e sujeitos tidos como realidades inquestionáveis. (ALBUQUERQUE JÚNIOR, 2014, p. 129).

Outrossim, é preciso não apenas modificar o olhar e sim tecer novos olhares. Não é necessário que eliminemos o que já existe de conhecimento, mas urge que desloquemos nossos focos interpretativos e observacionais, meio que agir como alguém que se queda, olhando por uma brecha de uma parede oblíqua para um corredor repleto de armários, os quais contêm discursos mil todos embaralhados a confundir a humanidade, que por este corredor passa e vive uma vida inteira sem sequer tentar dele sair, por meio de alguma fresta presente em suas prateleiras, a fim de olhar os discursos pelo lado de dentro da parede (sem ser visto), local que contém não a verdade/razão ${ }^{5}$, mas pelo menos constitui-se como um lugar mais "cômodo" e feliz, malgrado frustrante.

É necessária a construção de uma nova forma de criar, enxergar/interpretar e aplicar o Direito. Uma forma que, reconhecendo a existência de presunção iuris et de iuri no seio da possibilidade de promover a dignidade de todos:

[...] possibilite ao ator do Direito a compreensão da problemática jurídico-social, inserida no contexto de uma sociedade excludente como a brasileira, onde a dignidade da pessoa humana tem sido solapada desde o seu descobrimento. Dito de outro modo, os juristas brasileiros não podem (continuar a) comportar-se como o sujeito que está à beira do Vesúvio prestes a entrar em erupção. As lavas (da crise social) cobrirão a tudo e a todos, e, ao invés de construírem barreiras para evitar que as lavas cubram suas casas e a cidade, nossos juristas ficam tranquilos, tratando de arrumar o quadro de Van Gogh na parede. (STRECK, 2014, p. 98-99).

\section{CONSIDERAÇÕES FINAIS}

Neste singelo e exíguo artigo, por revisão bibliográfica qualitativa descritiva, perscrutou-se teorias que pudessem nos dizer, em tom crítico, qual nosso atual modelo de Direito, precipuamente Direitos Humanos, e quais os possíveis percursos em direção a um futuro com mais Justiça Social, sustentabilidade, responsabilidade social, cidadania, democracia e liberdade. Para finalizar o plexo de reflexões, deixamos uma indagação sobre ser mesmo o Direito uma "Ciência" ou não. 0 que essencialmente o Direito produz de bom para a sociedade, além de constituir-se como elemento social dissipador das ideologias dos poderosos e mantenedor da disparidade entre as forças sociais existentes?

5 Cremos que até hoje nada nem ninguém conseguiu dizer o que de fato são a verdade, a razão, a realidade, o real. Conquanto isso, para vivermos com alguma certeza, somos seguidores da perspectiva de Hanna Arendt (2012), para quem a única coisa real que conhecemos é o "chão de barro" em que pisamos, do resto nada sabemos. 
O Direito, do mesmo modo que outros sistemas sociais, é dominado pela ideologia, cujo objetivo - pelo menos a partir de um dos seus significados - é esconder as relações de dominação que imperam na sociedade civil, com o escopo de fazer com que os cidadãos aceitem sem contestação a dominação de uma(s) classe(s) sobre a(s) outra(s). Por isso é que [...] defendemos que o Direito não é uma Ciência, como algo dado de objeto e métodos próprios, haja vista que os "cientistas" do Direito, os juristas, não estão minimamente interessados pela busca da verdade, mas apenas pelo convencimento do outro. Outras Ciências mais apuradas [...] ririam da chamada "Ciência Jurídica" [...], quando ouvissem um "jurista-cientista” dizer que ele, para provar os seus postulados, reúne apenas os julgamentos favoráveis aos seus argumentos, nunca os desfavoráveis. (Grifos nossos)

Fica, portanto, a provocação: é o Direito de fato uma "Ciência” responsável por prover Direitos Humanos a todos - um conjunto de normas, instituições e de homens de boa vontade que fazem e cumprem leis para nos proteger a todos de alguns homens maus - ou é o Direito uma criação humana para ritualizar, oficial e sacralizadamente, os processos de dominação/exploração, subjugação e morte das pessoas que não integram a sala fechada da história onde sempre habitam os donos do capital/poder?6

\section{REFERÊNCIAS}

ABIB, José Antônio Damásio. Teoria moral de Skinner e desenvolvimento humano. Psicologia: reflexão e crítica, Porto Alegre, n. 14, 2001, p. 107-117. Disponível em: http://www.scielo.br/pdf/prc/v14n1/5211.pdf. Acesso em: 15 jan. 2018.

ABREU, Leonardo Lani de. A Ampliação do conceito de liberdade como pressuposto para maior efetivação dos direitos humanos. Revista Direitos Humanos Fundamentais (Mestrado em Direito - Centro Universitário UNIFIEO), n. 1, São Paulo: Editora da FIEO, 2012, p. 137-169. Disponível em: http://intranet.unifieo.br/legado/edifieo/index.php/rmd/article/view/668/704. Acesso em: 13 jan. 2018.

6 "O Direito, quando definido como o conjunto de regras que os homens são obrigados a respeitar sob a coação organizada da sociedade, aparece como uma ideia válida para todos os lugares, para todos os povos, em todos os tempos. Esta falácia é defendida com um único objetivo: apontar o Direito como algo desprovido de historicidade, ou seja, descrevê-lo como um filho sem genitor, que não é fruto de uma classe social dominante e de um Estado particular, que se amolda de acordo com os interesses econômicos desta classe. 0 propósito desse conceito é fazer crer que o Direito não só é assim como sempre foi, o que transfere passividade ao povo - diante das regras justas porque eternas - e acriticidade aos intelectuais - que acreditam e divulgam os postulados de uma suposta “Ciência Jurídica”' (BASTOS, 2012, p. 119). 
ALBUQUERQUE JÚNIOR, Durval Muniz de. Por uma história acre: saberes e sabores da escrita historiográfica. In: ALBUQUERQUE, Gerson Rodrigues de; ANTONACCI, Maria Antonieta (org.).

Desde as Amazônias: colóquios. V. 2. Rio Branco: Nepan, 2014, p. 111-133.

ALVES NETO, Francisco Raimundo. Diretrizes Curriculares Nacionais e o currículo do curso de Direito da UFAC: compreensão da experiência vivenciada por docentes e discentes. 2012. 159f. Tese (Doutorado em Educação). Universidade Federal de Minas Gerais - UFMG: Belo Horizonte, 2012. Disponível em: http://www.bibliotecadigital.ufmg.br/dspace/handle/1843/BUOS-8UBPVU. Acesso em: 12 jan. 2018.

ARENDT, Hannah. Origens do totalitarismo. Tradução de Roberto Raposo. São Paulo: Companhia das Letras, 2012.

BAKHTIN, Mikhail. Questões de literatura e de estética: a teoria do romance. Tradução de Aurora Bernardini. 7. ed. São Paulo: Hucitec, 2014.

BASTOS, Ronaldo. 0 conceito do direito em Marx. Porto Alegre: Fabris, 2012.

CABETTE, Eduardo Luiz Santos. Bakhtin e o direito: uma visão transdisciplinar. Porto Alegre, Núria Fabris, 2014.

COMPARATO, Fábio Konder. Capitalismo: civilização e poder. Revista Estudos Avançados, São Paulo, v. 25, n. 72, p. 251-276, maio/ago. 2011. Disponível em: http://www.scielo.br/pdf/ea/v25n72/ a20v25n72.pdf. Acesso em: 12 jan. 2018.

ESTEVÃO, Carlos Alberto Villar. Educação, justiça e direitos humanos. Educação e Pesquisa, São Paulo, v. 32, n.1, p. 85-101, jan./abr. 2006. Disponível em: http://www.scielo.br/pdf/ep/v32n1/ a06v32n1.pdf. Acesso em: 13 jan. 2018.

FERNANDES, Ângela Viana Machado; PALUDETO, Melina Casari. EDUCAÇÃO E DIREITOS HUMANOS: desafios para a escola contemporânea. Caderno Cedes, Campinas, v. 30, n. 81, p. 233249, mai./ago. 2010. Disponível em: http://www.scielo.br/pdf/ccedes/v30n81/a08v3081.pdf. Acesso em: 12 jan. 2018.

GRUPIONI, Luis Donisete Benzi. Índios: presente, passado e futuro. In: ARANTES, Vera Maria (org.). Cadernos da TV Escola: Índios do Brasil. Brasília: MEC, 2001, p. 5-29.

HABERMAS, Jurgen. Direito e democracia: entre facticidade e validade. Tradução de Fábio Bento Siebeneichler. 2. ed. Rio de Janeiro: Tempo Brasileiro, 2003. 
HEIDEGGER, Martin. Ser e tempo. Tradução de Márcia Sá Cavalcante Schuback. Petrópolis: Vozes, 2006.

HOUAISS, Antonio. Dicionário eletrônico Houaiss da língua portuguesa. Rio de Janeiro: Objetiva, 2009.

JUNQUEIRA, Eliane Botelho. Faculdades de direito ou fábricas de ilusões? Rio de Janeiro: Letra Capital (IDES), 1999.

LAFARGUE, Paul. 0 direito à preguiça. 2. ed. São Paulo: Hucitec, 2000. Versão online. Disponível em: http://livros01.livrosgratis.com.br/ma000018.pdf. Acesso em: 12 jan. 2018.

LUCIANO, Gersem José dos Santos. 0 índio brasileiro: o que você precisa saber sobre os povos indígenas no Brasil de hoje. Brasília: MEC/LACED, 2006.

LYRA, Roberto. Como julgar, como defender, como acusar. Belo Horizonte: Líder, 2015.

MASCARO, Alysson Leandro. Introdução à filosofia do direito: dos modernos aos contemporâneos. 2. ed. São Paulo: Atlas, 2008.

MORAES, Alexandre de. Direito constitucional. 12. ed. São Paulo: Atlas, 2002.

SARLO, Beatriz. Paisagens imaginárias: intelectuais, arte e meios de comunicação. Tradução de Rúbia Prates e Sérgio Molina. São Paulo: EDUSP, 1997.

SCHOPENHAUER, A. 0 mundo como vontade e representação. Rio de Janeiro: Contraponto, 2001.

SILVA, Ênio Waldir da. Sociologia jurídica. ljuí: Edições Unijuí, 2012.

SIQUEIRA, Carlos. Diálogos da liberdade. São Paulo: Quanta, 2009.

STRECK, Lênio Luiz. A relação "texto e norma" e a alografia do Direito. Revista Novos Estudos Jurídicos - Eletrônica, Porto Alegre, v. 19, n. 1, jan-abr., 2014, p. 1-20. Disponível em: http:// siaiap32.univali.br/seer/index.php/nej/article/view/5540/2945. Acesso em: 13 jan. 2018.

ZELIZER, Viviana. Dinheiro, poder e sexo. Cadernos Pagu, Campinas, n. 32, p. 135-157, jan./ June 2009. Disponível em: http://www.scielo.br/pdf/cpa/n32/n32a05.pdf. Acesso em: 13 jan. 2018. 


\section{Como citar este artigo:}

TELES, Tayson Ribeiro. MAIS DIREITOS HUMANOS E MENOS MISANTROPIA: POR UM DIREITO MENOS EGOÍSTA. Interfaces Científicas - Direito, Aracaju, v. 7, n. 2, p. 85-102, abr/mai/jun. 2019. DOI: 10.4025/actascieduc. v41i1.34184. Acesso em: 24 mar. 2019.

1 Docente EBTT, área Economia, do Instituto Federal do Acre - IFAC. Mestre em Linguagem e Identidade (Cultura e Sociedade) pela Universidade Federal do Acre - UFAC (2016), com dissertação no campo da análise do discurso político-jurídico brasileiro, e Bacharel em Direito pela mesma instituição (2017). Especialista em Gestão de Políticas Públicas, pela Universidade Federal de Ouro Preto - Minas Gerais (2016). Graduado em Finanças, pela UniSEB-Estácio/SP (2013).Licenciado em Matemática, pelo Ceuclar/ SP (2015).Vinculado aos Grupos de Pesquisa "História e religiões: Estudos das devoções populares na Amazônia sul ocidental" e "História e Cultura, Linguagem, Identidade e Memória", ambos da UFAC/CNPq.

E-mail: tayson.rteles@gmail.com

\section{(). (1) (2)}

Este artigo é licenciado na modalidade acesso abertosob a Atribuição-Compartilhalgual CC BY-SA

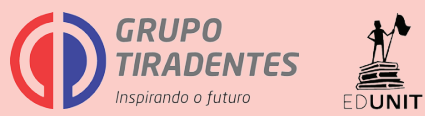


